\title{
Lupus Vulgaris and Zoon's Balanitis Occurring in the Same Patient: A Case Report Deepthi Ravi ${ }^{1}$, Vignesh $\mathbf{N ~ R}^{2}$, Jayakar Thomas ${ }^{3}$
}

${ }^{1}$ SAssistant Professor, ${ }^{2}$ Senior Resident, ${ }^{3} \mathrm{HOD}$ \& Professor Department of Dermatology, Venereology \& Leprosy, Sree Balaji Medical College \& Hospital, Bharath University, Chennai 600044, Tamil Nadu, India. jayakarthomas@gmail.com

*Corresponding Author: Jayakar Thomas, Department of Dermatology, Venereology \& Leprosy, Sree Balaji Medical College \& Hospital, Bharath University, Chennai, Tamil Nadu, India.

\section{Abstract}

The most common form of cutaneous tuberculosis seen in adults is lupus vulgaris. Zoon's balanitis is a chronic disease of uncertain origin which affects elderly or middle-aged uncircumcised men. Here we report a case of both lupus vulgaris over the left gluteal region and zoon's balanitis occurring in a 61-year-old uncircumcised male patient.

\section{INTRODUCTION}

Lupus vulgaris is a progressive, chronic, paucibacillary form of cutaneous tuberculosis which usually occurs secondary to a primary infection in a patient with high or moderate immunity ${ }^{1}$. It is usually caused by a lymphatic, hematogenous or contiguous spread from somewhere else in the body. In patients where the focus is not evident it can be due to a latent cutaneous focus occurring due to a prior bacteraemia which was silent ${ }^{2}$. It can also occur secondary to Bacillus Calmette-Guerin vaccination or to exogenous inoculation ${ }^{3}$.The most form of cutaneous tuberculosis in childhood in India is scrofuloderma and in adults it is lupus vulgaris ${ }^{4}$.

Zoon's balanitis usually affects older to middleaged uncircumcised men. It is also known as plasma cell balanitis of Zoon or balanitis circumscripta plasmacellularis ${ }^{5}$. The etiological factors are proposed to be irritation due to retention of smegma and urine, trauma, heat, and friction.

\section{CASE REPORT}

A 61 year old circumcised male patient came with complaints of a raised skin lesion over the left gluteal region since the last 5 years years and history of an erythematous lesion over the glans penis since thelast 6 months. The patient developed a small papule over the gluteal region 5 years back which progressed to form a plaque of about $8 * 5 \mathrm{~cm}$. History of recurrent episodes of ulceration and crusting over the lesion present. The patient had dryness over the glans followed by loss of skin and erythema over the affected area. History of bleeding on contact with clothing present. The patient was diabetic since the last 1 year on treatment. The patient's father had history of tuberculosis.

On examination a pigmented plaque of about $8 * 5 \mathrm{~cm}$ with areas of atrophy and mild scaling was present over the left gluteal region Figure 1. Diascopy did not reveal any findings. A well-defined, shiny erythematous plaque which bled on touch was present over the glans penis Figure 2. There was no lymphadenopathy. Systemic examination was within normal limits.

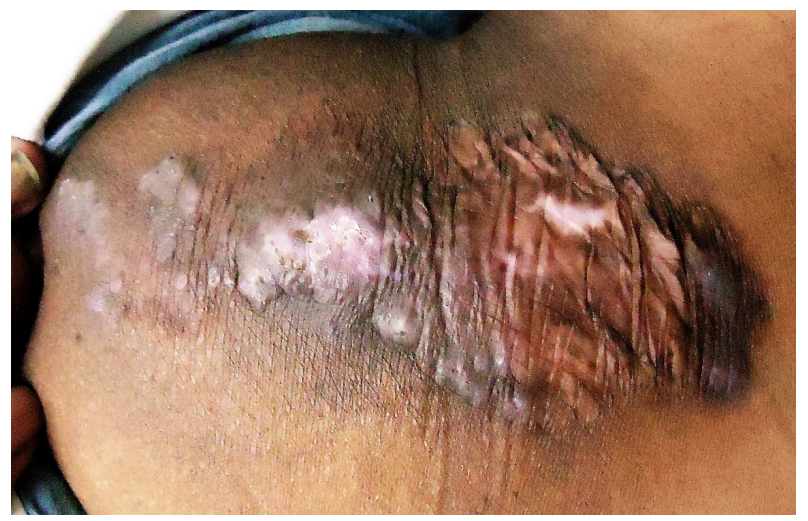

Figure 1. Left gluteal region of the patient showing a pigmented plaque of $8 * 5 \mathrm{~cm}$ with few areas of atrophy and mild scaling 


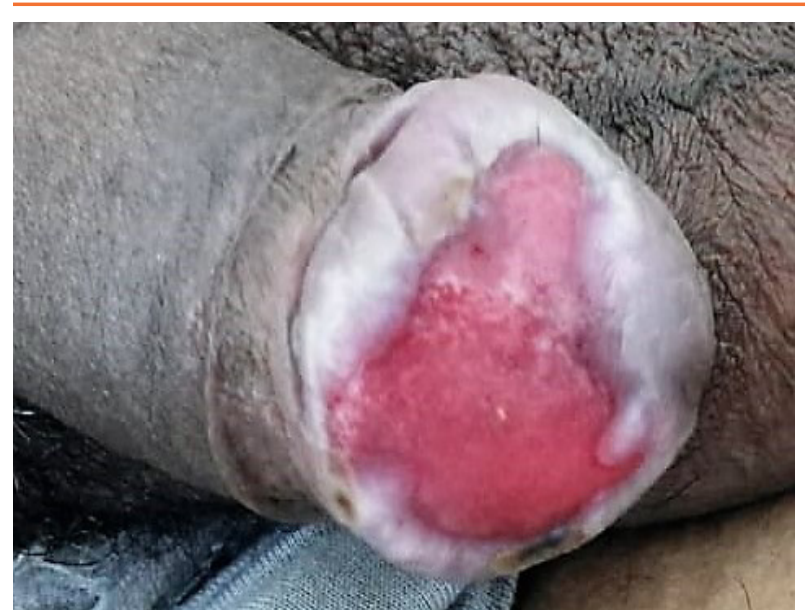

Figure 2. Glans penis showing a well-defined shiny erythematous plaque
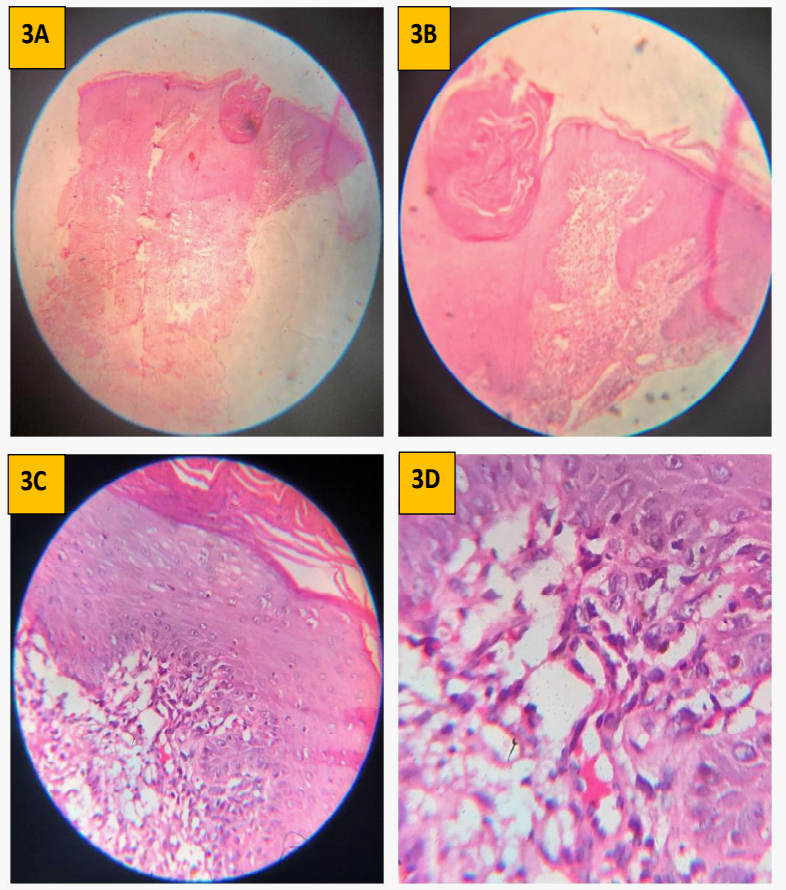

Figure 3. Formalin fixed, $H \&$ E stained section of skin taken from the pigmented plaque over the gluteal region.

3A. Scanning view showing hyperplasia of the epidermis along with granuloma formation and inflammatory infiltrate in the dermis.

3B. $10^{*} 100 x$ view showing hyperkeratosis, acanthosis and papillomatosis along with granuloma formation in thee dermis.

3C. $40 * 100 x$ view showing a closer view of the epidermal hyperplasia and the granuloma in the dermis showing Langhans giant cells.

3D. A closer view of the Langhans giant cells with peripheral arrangement of nuclei.
Biopsies were taken from both the plaques over the gluteal region and glans penis.

The biopsy taken from the pigmented plaque showed epidermal hyperplasia with hyperkeratosis, acanthosis

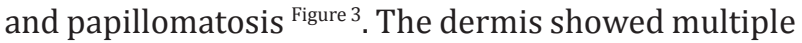
granulomas with Langhans giant cells. A Mantoux test was done which was positive with an induration of $11 \mathrm{~mm}$.

The biopsy taken from the erythematous plaque over the glans penis showed a subepidermal split. The epidermis showed spongiosis and lozenge shaped keratinocytes. The dermis showed diffuse

inflammatory infiltrate with multiple plasma cells and erythrocytes.

Based on the clinical and histopathological features a diagnosis of lupus vulgaris over the gluteal region and zoon's balanitis over the glans penis.

The patient was started on antituberculous therapy. The patient was already circumcised and hence was started on topical tacrolimus for the Zoon's balanitis.
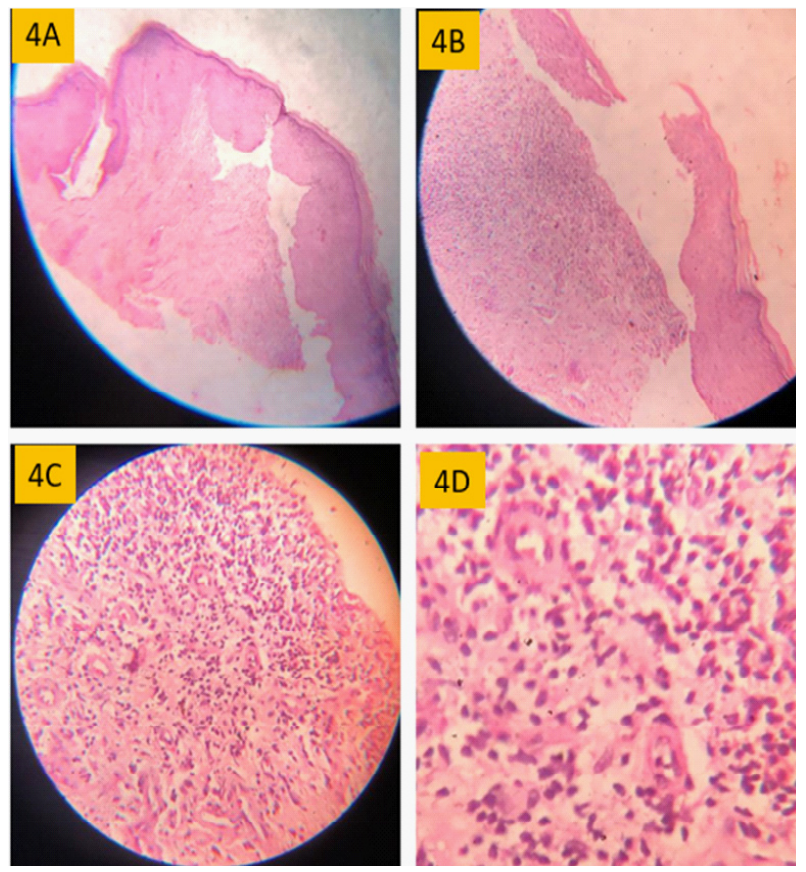

Figure 4. Formalin fixed, H\&E stained section of skin taken from the erythematous plaque over the glans penis. 4A: Scanning view showing subepidermal cleavage. 4B: $10^{*} 100 x$ view showing spongiosis and lozenge shaped keratinocytes. A diffuse inflammatory infiltrate is seen in the dermis.

4C: $40^{*} 100 x$ view showing an inflammatory infiltrate with multiple plasma cells and erythrocytes.

4D: A closer view of the plasma cells. Cells with a peripheral and dark staining nucleus are seen. 
Lupus Vulgaris and Zoon's Balanitis Occurring in the Same Patient: A Case Report

\section{DiscusSION}

In India cutaneous tuberculosis most commonly affects the gluteal region and the extremities ${ }^{6}$ unlike in Europe where the most common sites are the head and neck. This pattern most commonly occurs due to external inoculation. Since the patient's father had history of pulmonary tuberculosis that may be the source of infection.

The clinical patterns of cutaneous tuberculosis depend on the local tissue response to the infection. The types include plaque, ulcerative and mutilating, vegetating, tumour like and papular nodular forms. This patient shows plaque type of lupus vulgaris which is also the most commonly reported type of lupus vulgaris. Spontaneous involution of lesions can occur with subsequent new lesion development within the old scars. Therapy is required for complete resolution of the lesions. All patients with cutaneous tuberculosis need to be reported and also treated with standard anti-tuberculous therapy.

The clinical criteria for diagnosis of Zoon's balanitis by Kumar et al are erythematous patches on the glans, prepuce or both, lesions present for more than 3 months, absence of lesions suggestive of psoriasis or lichen planus elsewhere on the body, poor response to topical therapies given for a minimum period of 4 weeks and absence of concurrent infections ${ }^{7}$. The patient must have three of these five criteria to be diagnosed as Zoon's balanitis. Our patient satisfied the first three of these criteria.

The treatment for Zoon's balanitis includes topical steroids, topical calcineurin inhibitors, topical imiquimod, topical fusidic acid, Carbon dioxide and Er: YAG lasers and photodynamic therapy. Circumcision is the definite treatment and there is prolonged remission after circumcision. Since this patient is already circumcised at the age of 5 years, he was treated with topical tacrolimus.

\section{ConClusion}

Lupus vulgaris and Zoon's balanitis have not been reported together in the same patient till now. Even though their respective pathogeneses are not related, this case has been reported for its rarity.

Zoon's balanitis though more common in uncircumcised men can still be seen and have been reported in circumcised men.

\section{REFERENCES}

[1] Yates VM. Mycobacterial infection. In: Burns T, Breathnach S, Cox N.editors. Rook's Textbook of Dermatology. $8^{\text {th }}$ ed. Oxford: Blackwell Science Ltd; 2010. pg. 31.16-9.

[2] Marcoval J, Servitje O, Moreno A et al. Lupus vulgaris. Clinical, histopathologic, and bacteriologic study of 10 cases. J Am Acad Dermatol 1992;26: pg no. 404-7

[3] Tan HH, Seow CS. A review of cutaneous granulomas and lupus vulgaris following BCG vaccination in a skin hospital in Singapore. Ann Acad Med Singapore 2002;31:pg no.663-5

[4] Kumar B, Rai R, Kaur I et al. Childhood cutaneous tuberculosis: A study over 25 years from northern India. Int J Dermatol 2001; 40: pg no.26-32.

[5] Cooper SM, Wojnarowska F. Anogenital (nonvenereal) disease. In: Bolognia JL, Jorizzo JL, Schaffer JV, editors. Dermatology. 3rd ed. United States: Elsevier; 2012. pp. 1171-86ca

[6] Sehgal VN, Wagh SA. Cutaneous tuberculosis. Current concepts. Int J Dermatol 1990;29: pg no:237-52

[7] Kumar B, Narang T, Dass Radotra B, Gupta S. Plasma cell balanitis: Clinicopathologic study of 112 cases and treatment modalities. J Cutan Med Surg. 2006; 10:11-5.

Citation: Deepthi Ravi, Vignesh N R, Jayakar Thomas. Lupus Vulgaris and Zoon's Balanitis Occurring in the Same Patient: A Case Report. Archives of Dermatology and Skin Care. 2018; 1(1): 4-6.

Copyright: (C) 2018 Deepthi Ravi, Vignesh N R, Jayakar Thomas. This is an open access article distributed under the Creative Commons Attribution License, which permits unrestricted use, distribution, and reproduction in any medium, provided the original work is properly cited. 